\section{THE SATELLITE OF VENUS 1}

$A \mathrm{~N}$ indirect result of the recent Transit of Venus has $A$ been the revival of a nearly forgotten but not uninteresting speculation as to the possible existence of a satellite accompanying her. Nothing of the kind was observed on the late occasion, but the planet's path was so far from central that an attendant might readily have remained outside the solar disc; and therefore, though the negative evidence, if it had required additional strength, would have received it from this non-appearance, it would not have been rendered absolutely conclusive on that ground alone; and, so far as the Transit is concerned, there is still room for an essay like that before us, which, previous in composition though subsequently published, advocates the affirmative opinion. That opinion, after so many years of additional observation since Lambert's memoir in 1777 , is not likely to find favour with astronomers now, and certainly will not be established by the present treatise. It is an unpleasant task to express any other than a favourable estimate of any work undertaken with a view to enlarge the boindary of knowledue; but in the present instance it is unavoidable. There is, indeed, a very considerable accumulation of historical malter, and there are some pleasant anecdotes, and a few valuable and little known facts; but the materials of some portions at least are neither complete nor accurate; the pretermission of recent discoveries-especially spectroscopic-is sometimes simply unaccountable; and the hypotheses occasionally partake of an extravagance that outstrips all probability. The subject is, however, as has been remarked, not devoid of some interest, nor, to say the truth, disentangled from some perplexity of an obstinate character; and it is worthy of a more satisfactory elucidation, which might be comprised in a narrow compass, as its literature is not extensive. A few remarks only can be attempted here.

That something strongly resembling a satellite has been occasionally seen near. Venus, especially about the middle of the last century, is beyond a doubt. It is equally certain, and familiar to all experienced observers, that reflected images, or technically "ghosts," may, under certain circumstances, be formed in the eye-piece of the telescope, and might be the means of causing deception: and the whole matter is reduced to the simple inquiry, whether all the recorded instances admit of this easy explanation ; though, if they do not, it must be remembered that the existence of a satellite would not necessarily follow.

The Abbot Hell, who published an elaborate dissertation on the subject in the appendix to the Vienna Astronomical Ephemerides for 1766 , seems to have been the first to study systematically the formation of telescopic ghosts. The Vienna Observatory was possessed in those days of two good English telescopes, left to it in 1757 by Cardinal de Trautson; a $2 \mathrm{ft}$. Gregorian, and a $4 \frac{1}{2} \mathrm{ft}$. Newtonian. About December in that year, the Abbot, examining Venus with the former instrument and a power of 70 or 80 , perceived a star of an ill-defined aspect near it like a little comet, but as it was invisible both in that Newtonian and in another of the same construction of $4 \mathrm{ft}$., he referred it to a reflection from the interior of the tube. In March 1758 , Venus being at her greatest elongation, the illusion returned, on which he blackened the tube, and for some days did not see it again; but when at length it reappeared, on moving his eye very gently towards the eyepiece he found it change into a perfect image of a satellite with the phase of the primary. Beyond the limit of barely half a line either way from this position, it was invisible. When Venus occupied the centre of the field, x "Der Venusmond," \&c., von Dr. F. Schorr. Braunschweig, ז375, pp. 186. this "spectrum," as he calls it, was near the edge; as he moved his eye round, or up and down, the image moved the same way, generally disappearing in the neighbourhood of the planet. A set of experiments instituted in consequence satisfied him that this image was formed by rays reflected first from the convexity of the "pupil" (cornea), and a second time from the concave face of the meniscus lens which in this case formed the eye-glass, though it would be shown by any eye-piece possessing a surface concave towards the retina. Cases were even possible, but difficult in management, when an image might be seen, though the object was not in the field; but this was formed by rays passing outside the telescope, and the ghost would be inverted and of much smaller dimensions. The magnitude of the image would depend on the proportion of curvature of the reflecting surfaces. This being once understood, the Abbot found that he could always produce, for himself or others, a spurious satellite of Venus, or Mars, or Jupiter, under the following essential conditions:- That the power should not be less than 50 or 80 , or the image would be too minute to be visible, or would only resemble a small star; -that the eye must be placed at a definite distance from the eyeglass, and be moved most deliberately and cautiously backwards and forwards to find that point, the limit of visibility being sometimes only a quarter of a line either way ; - and that the eye must be a little oa one side of the optical axis, or the image will coincide with its primary. And it becomes readily intelligible why an observer, ignorant of these conditions, may never be able to recover an image which he had once accidentally seen. Thus far, in substance, the astronomer of Vienna, who certainly deserves credit for his ingenious and careful investigation. His reasoning is, nevertheless, a curious and instructive exemplification of the way in which a preconceived opinion may block up the mental view, and prevert a sound argument from being carried out to its legitimate consequences.

We are now in a position to examine how far this criterion is applicable to the recorded phenomena. Of these, Dr. Schorr has enumerated sixteen, in a table taken apparently from Lambert, but with the addition of an observation by Andreas Meier (Mayer). Hell had given three from Fontana, but Lambert seems to have thought one only of any consequence, and even this may well be omitted, leaving the following for our consideration.

The name of Cassini at the head of them at once commands attention, but there is nothing in his two observations in 1672 and 1686 that does not lend itself to Father Hell's hypothesis, excepting the care and experience of such an observer, who must have been familiar with every telescopic defect. The observation of Meier, which seems to have lain unnoticed in the Astron. Fahrbuch, I788, till brought forward by Schorr, is on that account worthy of being cited in full. "I759, May 20, about $8 \mathrm{~h} .45 \mathrm{~m}$. $50 \mathrm{~s}$., I saw above Venus a little globe ot far inferior brightness, about $1 \frac{1}{2}$ diam. of Venus from herself. Future observations will show whether this little globe was an optical appearance or the satellite of Venus. The observation was made with a Gregorian telescope of thirty inches focus. It continued for half an hour, and the position of the little globe with regard to Venus remained the same, although the direction of the telescope had been changed." During so lengthened an observation it seems natural to suppose that the eye must have been repeatedly removed and replaced, which could not have occurred without the detection of an optical illusion.

In $176 \mathrm{I}$, when the expected transit drew attention to Venus, Montaigne, at Limoges, was persuaded to undertake the inquiry, though he had little taith in the existence of the satellite, and was not greatly disposed to enter upon an examination in which so many great men had failed. However, on May 3 he saw a small cresceat 
$2 O^{\prime}$ from Venus; it is expressly stated that the observation was repeated several times, and that after all he was not certain if it was not a small star; which, with a power of between forty and fifty, was not surprising. The next evening and on the 7 th and $I I t h$ it was again seen, rather more distant, and each time in an altered position, but with the same phase as its primary; and on the 7 th it was seen, and even much more distinctly, when Venus was not in the field. The improbability is obvious of such persistency in an illusion so readily detected. The cause may indeed have lain in the object-glass; such telescopes have been known. Wargentin, at Stockholm in the same year, found that his instrument produced a deception from this cause; and the 6.inch Cauchoix achromatic at Rome showed minute comites to bright stars a little too frequently for the credit of those who trusted it. Montaigne's changed position-angles may be thought to indicate this cause of error, as his 9 - $\mathrm{ft}$. refractor probably admitted of rotation in its bearings, but it is a singular coincidence that these changes should all have been in the direction of orbital revolution, and still more, in such proportions as to be reconcilable with Lambert's calculated period of about eleven days ; and it is quite unintelligible that he should not have subsequently detected the fault in his telescope, as from his estimation of angles and distances he was evidently not a novice in observation. Three years later, in 1764 , Rödkier, in Copenhagen, saw such an appearance on two evenings with a power of thirty-eight on a $9 \frac{1}{2} \mathrm{ft}$. refractor; on the latter occasion with a second telescope also. There is little in this to contravene the Vienna theory, especially as this second telescope had a coloured meniscus eye-glass, and he failed in finding it with two other instruments : but it is more remarkable that on two evenings a week later the same telescope told the same tale to four different observers, one of whom was Horrebow, the Professor of Astronomy, and who, we are assured, satisfied themselves by several experiments before the second observation that it was not a deception. That the necessary conditions for its being such could have been maintained before so many eyes, is, notwithstanding its admitted pale and uncertain aspect, what could not possibly have been anticipated. But we have not yet done with this temporary outbreak, so to speak, of visibility. Before this month of March was ended, Montbarron at Auxerre, far removed from all possibility of communication, and with a very different kind of telescope, a Gregorian reflector of thirtytwo inches, which of course was fixed as to its optical axis, perceived on three separate evenings, at different position-angles, something which, though it had no distinguishable phasis, was evidently not a star, and which he never could find again.

There remains still the observation of the celebrated optician Short. It is indeed chronologically misplaced here, but has been intentionally deferred as affording the strongest point in the whole affirmative evidence. As his own account is an interesting one, and has seldom, if ever, been reprinted, our readers may not be displeased to see it kere as it stands in Phil. Trans. vol. xli. :-

"An Observation on the Planet Venus (with regard to her having a satellite), made by Mr. James Short, F.R.S., at sunrise, October 23, 1740.-Directing a reflecting telescope of 16.5 inches focus (with an apparatus to follow the diurnal motion) towaids Venus, I perceived a small star pretty nigh her; upon which I took another telescope of the same focal distance, which magnified about fifty or sixty times, and which was fitted with a micrometer in order to measure its distance from Venus, and found its distance to be about $10^{\circ} 2^{\prime} \mathrm{O}^{\prime \prime}($ sic). Finding Venus very distinct, and consequently the air very clear, I put on a magnifying power of 240 times, and to my great surprise found this star put on the same phasis with Venus. tried another magnifying power of 140 times, and even then found the star under the same phasis. Its diameter seemed about a third, or somewhat less, of the diameter of Venus ; its light was not so bright or vivid, but exceeding sharp and well defined. A line, passing through the centre of Venus and it, made an angle with the equator of about eighteen or twenty degrees. I saw it for the space of an hour several times that morning; but the light of the sun increasing, I lost it altogether about a quarter of an hour after eight. I have looked for it every clear morning since, but never had the good fortune to see it again. Cassini, in his Astronomy, mentions much such another observation. I likewise observed two darkish spots upon the body of Venus, for the air was exceeding clear and serene."

It has been justly asked by Schorr whether this observer, who was the greatest optician of his time, must not have known his telescopes better than to mistake the reflection of Venus on the eyeglass for a satellite? And Lambert puts the case very strongly, remarking that Short had the object before him for a whole hour with greatly varied powers, and it is not probable that he kept his eye immovable all the time, and after every change in the telescope replaced it at the precise point where the apparent position and distance from Venus would continue unaltered, especially as he used so high a power, with which the slightest change would have been remarked, and a micrometer, the employment of which would have necessarily implied movement in the eye. Lambert might have further strengthened his argument had he had an opportunity of consulting the original record, which shows that another telescope was employed, making in all four eye-pieces, and that Short viewed it not continuously, but at intervals during an hour, increasing every time the chance of detection; nor should the important consideration be overlooked that, with the higher powers, the apparent motion of the planet through the field would be rapid enough to give the illusion a movement in the reverse direction, which would unmask it at once. An examination of one of Short's reflectors might be necessary to decide whether with his power of 240 (he was said to have considerably over-rated his magnifiers) the field would have included the attendant with the primary.

The evidence against Father Hell's explanation had even previously become very formidable. The conditions under which his "ghost" is visible are so restrained, the limits so narrow, that there is considerable presumption in any individual case against such an illusion having been formed, or at least against its having passed unchallenged, when a trifling change in the supposed obliquity of indirect vision would at once shift the position of the false image with respect to its origin, and an equally minute alteration in the distance of the eye would deface or obliterate it. But if this is so in each separate instance, the enumeration of so many, with instruments and observers so varied, increases the improbability afresh at every remove, and the careful observation of a man like Short is peculiarly conclusive against the possibility of deception, at least from the assigned cause.

Thus far the advocates of a satellite have it their own way; and to what has been said they would add some curious facts as corroborative evidence. The object, when its size has been remarked, has always been recorded of the same magnitude, one-fourth, or less than one-third, of its primary. It showed itself seven times in one month (March 1764), at a period when telescopes were no longer in their infancy, and in two places at a great distance from each other. And its position-angles, which chance would have placed anywhere, agree sufficiently well with orbital revolution to admit of the calculation of a period, which Lambert has given at I Id. 5h., to which, however, Schorr prefers his own of 12.17d. Many astronomical details are probably accepted among us for which there are no stronger grounds of belief.

But it is one thing to invalidate an opponent's conclu- 
sion-another, to establish one's own. As we have already remarked, the abandonment of Hell's solution is not the demonstration of a satellite; and we have yet to hear the opposite side. Some adverse points we have noted as we have passed along; and we might have added the fact that at the epoch of Rödkier's second observation Uranus and Venus were not far apart; perhaps "within blundering distance." But of course the main strength of the denial lies in the fact that, though the alleged appearance can require but little optical advantages, it has been so frequently sought in vain through a long series of years. During that very spring of 1764 , when the primary occupied an especially favourable position, it was very carefully looked for by many observers-among others, the acute and experienced Messier, but nowhere seen except at Copenhagen and Auxerre. Cassini and Short, with interest awakened by their own apparent success, could never with all their diligence recover it; and the latter, twenty-three years after his own striking observation, was thought by Lalande, then in London, to disbelieve the satellite's existence. Not to mention Bianchini and others, the elder Herschel never saw a trace of it ; nor Schröter, the close observer of Venus during fifteen years; nor Harding, nor Struve, nor Lamont, Smyth, De Vico, Secchi, or any other of the first observers armed with the first telescopes of modern times. And though the subject has now ceased to attract attention, yet, in the unprecedented multiplication of observers and instruments, it would hardly have had a chance of escare. On the whole, therefore, though the evidence may exclude the intrusion of an ordinary "ghost," it seems irresistible against the reality of a satellite.

What, then, was that which was seen? for that some. thing really has been seen, the character of some at least of the witnesses renders a certainty. A reflection in the telescope independent of the position of the eye would have been always visible as a permanent defect; and the fact of its never recurring is equally adverse to the idea of a satellite, and that of an instrumental deception. The only alternative which remains would seem to be that of atmospheric reflection, or "mirage." There would certainly be some difficulty in finding a parallel among recorded facts, though Brewster, if I recollect aright, speaks of having once seen two images of the crescent moon; but the known instances of atmospheric illusion are sore of them so very strange and inexplicable, and yet so abundantly attested, that we may possibly, though with little confidence, seek in this direction a solution of the ancient mystery.

Before concluding these remarks, I may be permitted to relate something which fell under my own notice many years ago, and which may perhaps have some connection with the present subject. The observation which I am about to describe took place in the year 1823 ; it was not reduced to writing till nine years afterwards, but the recollection of it was then very vivid and fully to be trusted; and a small diagram of the relative position of the objects made at the time in the margin of a pocketbook of that year fixes the date to May 22. Until that evening I had never seen the planet Mercury, but finding that he was then in a favourable position I looked out for him with a little common hand-telescope (my near sightedness and the want of an eye-glass preventing me from detecting him otherwise), and soon found him low in the sunset horizon. The telescope in question had a good achromatic object.glass of $I^{\prime} 3$ inch aperture and $I_{4}$ inches focus, and was fitted with a terrestrial eye-piece, magnifying perhaps thirteen or fourteen times ; it was a favourite instrument in those early days, and I had succeeded in detecting with it several of the brighter nebulæ and clusters, especially, at the extreme limit of visibility, the large nebula in Triangulum (M. 33). When I had looked at Mercury, I turned to Venus, then high in the S.W., and saw a star, exactly resembling Mercury, or a minia- ture Venus, $p$ or $s p$ the planet, at pa short distance, perhaps $20^{\prime}$ or $30^{\prime}$, and $\frac{1}{3}$ or $\frac{1}{4}$ of its diameter, or rather its impression on the eye, as of course with so low a power the disc of the planet could not be well made out. I had, when I wrote, a very distinct recollection of its great resemblance to Mercury. My mother, who had an excellent sight, coming into the garden, I showed her Mercury and this appearance with the glass, and she not only saw it readily, but we both believed afterwards that she perceived it without that aid. On the next evening, or more probably an the next but one, I could not find it again. As far as I can ascertain, I had in those early days no knowledge of the suspicion that had been entertained of a satellite: and I did not enter it, as in that case I should have done, in a little note-book of remarkable phenomena that I kept. Through the kindness of Mr. Lynn I have been enabled to ascertain that the star $\in$ Geminorum was not far from the planet on that day, only about $30 \frac{1}{2}^{\prime}$ further S., which would agree very fairly in that direction, but lying $6 \frac{1}{2} \mathrm{~m}$. more to the $\mathrm{E}$. Independently of this discrepancy-a serious one, for I have no doubt of the $p$ or $s p$ position of the satellite, not only clearly remembered but shown in the little diagram-it does not seem probable that a star of $3-4$ mag. should have been so conspicuous in such an instrument in the twilight. I have no note of the hour, but as Mercury had not sunk into the smoke of the town (Gloucester) in the W. horizon, it must have been comparatively early, and at that time of year the twilight is strong. It may be too hazardous under all the circumstances to include this with the other observations of the pseudo-satellite, but there seems no reason why it should pass into entire oblivion.

T. W. WEBB

\section{THE MISSING LINK BETWEEN THE VER- TEBRATES AND INVERTEBRATES ${ }^{2}$}

THE views which Dr. Dohrn has recently put forth as to the details of the steps by which the vertebrate stock arose out of an ancestry not very much unlike the existing Annelids, are of such interest that, notwithstanding previous reference to the subject, no apology is needed for presenting the readers of NATURE with a condensation of the main argument contained in "The Origin of Vertebrata."

Dr. Dohrn first draws attention to the correspondences between vertebrate and insect embryos, which have been too little regarded in consequence of our designating the nervo's side in the one as dorsal, in the other as ventral. Yet the facts that, in both, the nervous system is developed on the convex side of the embryo and acquires a strong convex flexure anteriorly, and that the body-cavity is finally closed up on the side of the body opposite to the nervous system, point to a common origin at a comparatively high level. The surface of the animal which is called ventral is determined by the presence of the mouth on that surface; and if any Vertebrates had a mouthopening between the brain and the spinal cord on the dorsal surface, that dorsal surface would necessarily become ventral. Since, moreover, the ancestors of the Vertebrata must have had a nervous ring surrounding their gullet, it would appear more reasonable to suppose that the mouth-opening had been changed in the course of development than that the situation of the nervous centres had been altered. We are thus led to look for traces of an old mouth-opening on that surface of the early Vertebrates which corresponded to our dorsal surface, and to seek reasons for regarding our present mouth as a comparatively modern development.

Dr. Dohrn believes that the old mouth passed through the nervous centres between the crura cerebelli, or more

1 Der Ursprung der Wirbelthiere und das Princip des Functionwechsels: Genealogische : kizzen von Anton Dohrn. (Leipzig: Engeluann). 